\title{
Weather-Based Forecasting of Rhizoctonia Web Blight Development on Container-Grown Azalea
}

\author{
Warren E. Copes, USDA-ARS Thad Cochran Southern Horticulture Laboratory, P.O. Box 287, Poplarville, MS 39470
}

\begin{abstract}
Copes, W. E. 2015. Weather-based forecasting of Rhizoctonia web blight development on container-grown azalea. Plant Dis. 99:100-105.

The most reliable approach for timing fungicides to control Rhizoctonia web blight on container-grown azalea has been a fixed calendar date. The purpose of this study was to model periods when a preventive control could be applied in advance of significant increases in leaf blight intensity (LBI) in response to a daily accumulated risk value indicating conducive conditions of temperature (18 or more hours between 20 and $30^{\circ} \mathrm{C}$ when maximum temperature is less than $35^{\circ} \mathrm{C}$ ), leaf wetness (16 or more hours), and/or rainfall (greater than $6.7 \mathrm{~mm}$ above the maximum daily irrigation). Analysis used weather measurements taken every 30 minutes from 11 site-year datasets from 2006 to

2011, and weekly or biweekly LBI assessments. Six developmental site-year datasets were analyzed using receiver operating characteristic (ROC) curve procedures to evaluate models. Only a single model predicted true positives and negatives significantly greater than a 50:50 probability. Subsequently, five site-year validation datasets were evaluated. Similar results were obtained from both the developmental and validation datasets, which produced ROC areas of $0.7715(P=0.0120)$ and $0.8393(P=0.0034)$, respectively. The practical application of weather-based forecasting for management of web blight in nurseries is discussed.
\end{abstract}

Rhizoctonia web blight, caused predominately by binucleate Rhizoctonia AG-U (teleomorph Ceratobasidium D.P. Rogers), occurs annually on container-grown azalea (Rhododendron spp.) in the southern and eastern United States $(2,13,22)$. Web blight symptoms typically appear in July and August, but can occur as early as June and as late as September $(2,7,8,14)$. The most common symptom is complete foliar necrosis of individual leaves, with marginal leaf necrosis occurring less frequently. Leaves commonly dehisce within one to several weeks after becoming necrotic, but may cling to the plant via the pathogen's mycelial network, hence the name web blight. Symptoms, unnoticed by most observers, typically appear first during early summer as a few necrotic leaves in the interior canopy of the shrub. The number of blighted leaves progresses outward through the canopy as the season progresses (7). Plants may be lost due to severe stem blight and plant mortality. Rhizoctonia web blight of azalea is managed primarily through the application of fungicides, typically two to three applications per year $(2,5)$. A common practice is for producers to apply fungicide in early July, particularly when afternoon rains are prevalent or immediately following a severe outbreak of leaf blight $(2,5)$. Only in the last 2 years have some producers started applying fungicides on a calendar-based schedule. Fungicides have consistently arrested disease development with successful recovery of leaf growth even after a severe web blight outbreak. A predictive model would improve timing of fungicides to reduce severe outbreaks.

Temporal studies on Rhizoctonia web blight on azalea in southern Mississippi have reported several different weather conditions that are conducive for disease development (4-8). Rhizoctonia web blight development on azalea was initially correlated with air temperatures between 25 and $30^{\circ} \mathrm{C}$ for 6 to $8 \mathrm{~h}$ per day, relative humidity $\geq 95 \%$ for $>8 \mathrm{~h}$ per day, and/or leaf wetness for $>6 \mathrm{~h}$ per day (7). Further investigation showed that minimum and maximum daily temperatures at less than $20^{\circ} \mathrm{C}$ and higher than $35^{\circ} \mathrm{C}$, respectively,

Corresponding author: W. Copes, E-mail: warren.copes@ars.usda.gov

Accepted for publication 16 July 2014.

http://dx.doi.org/10.1094/PDIS-01-14-0033-RE

This article is in the public domain and not copyrightable. It may be freely reprinted with customary crediting of the source. The American Phytopathological Society, 2015. were associated with a low disease risk and moisture variables were relatively poor predictors of weekly changes in web blight severity (8). Further investigation found that web blight control was obtained in two of three field trials when the first fungicide application of the season was applied within 2 days after a 7-day period with three or more rainfalls greater than $0.63 \mathrm{~cm}(5)$. The importance of moisture was further demonstrated in a controlled environmental study (4), when moderate to severe web blight symptoms developed in response to $16 \mathrm{~h}$ or more durations of daily leaf wetness. Despite the irregular relevance of weather variables, the information was collectively used to define conducive weather variables. Temperature range and duration $(7,8)$, maximum temperature limit (8), leaf wetness duration (4), and rainfall (5) were used to calculate daily risk values and incorporated in the proposed predictive model.

Weather conditions conducive for Rhizoctonia web blight have been reported on soybean $(3,28,29)$, maize (1), and perennial ryegrass turf $(12,15)$. Fidanza et al. (12) developed a warning model that used the mean daily relative humidity and minimum daily air temperature to accumulate daily points. The points were accumulated until a threshold value was reached that signaled need for a fungicide application to control foliar blight of Rhizoctonia brown patch on ryegrass turf (12). Copes et al. (5) showed that web blight on container-grown azalea could be controlled when fungicides were applied either on a fixed calendar schedule, after a disease threshold of 16 or more blighted leaves was reached, or after three or more rainfalls greater than $0.63 \mathrm{~cm}$ occurred within the past 7 days. While these criteria were tested as individual treatments, they likely could be used in combination. Thus, the literature suggests a possibility for a predictive model for Rhizoctonia web blight on azalea, even though specific environmental variables have not readily been correlated with web blight development on container-grown azalea.

The rate and degree of web blight development differed between wet, moderate, and dry years, and weather variables of temperature, rainfall, and duration of leaf wetness do influence disease development and control (4-8). Rhizoctonia web blight on azalea behaves like a polycyclic disease $(7,8,14)$. Mycelium serves as primary and secondary inoculum. In the southeastern United States, mycelium persists in the azalea canopy 12 months of the year (6). The mycelium density declines by early spring and builds up again by summer, probably in a cyclic growth pattern that correlates with episodic leaf blight development. Binucleate Rhizoctonia 
fungi that cause web blight produce psuedosclerotia, but it is unclear if it plays a distinct role as primary inoculum (6). The presence of basidiospores has not yet been determined. Furthermore, three subprocesses (mycelium growth along limbs, infection cushion development, and leaf necrotization) possibly occur simultaneously, which makes prediction inherently more difficult than for foliar fungi with more discrete cycles. Receiver operating characteristic (ROC) curve analysis is a procedure that has been used to compare decision models and identify predictor thresholds for several plant diseases $(10,11,19-21,23,25-27)$. The objective of the research reported here was to develop and evaluate a weatherbased web blight predictive model from data collected during 11 site-years that represent weather conditions ranging from wet (2006), to moderate (2007 and 2008), to dry (2009 to 2011). Information theory statistics were used to select and validate a weather-based web blight model.

\section{Materials and Methods}

Plants and trials. Data were collected from temporal disease development trials (2006 to 2008) and fungicide timing trials (2009 to 2011$)$ performed over 6 years $(5,8)$. The temporal disease development trials were conducted at three locations, the USDA-ARS Thad Cochran Southern Horticultural Laboratory (TCSHL) in Poplarville, MS, and one commercial nursery each in southern Mississippi and Alabama (MSn and ALn, respectively). The fungicide timing trials were conducted at two locations, TCSHL and the Auburn University Ornamental Horticulture Research Center (OHRC) in Mobile, AL. A total of 12 site-year datasets were gathered, eight from 2006 to 2008 and four from 2009 to 2011. In all experiments, Azalea 'Gumpo' (either 'Gumpo Pink' or 'Gumpo White') of 16-month-old nursery stock in 2.7-liter containers were purchased from commercial nurseries. In 2006 to 2008, plants were maintained in 2.7-liter containers. In 2009 to 2011, plants were transferred into a comparable pine bark media in 6.2-liter containers. Plants typically were fertilized in May with Osmocote 15-9-12 at $10 \mathrm{~g}$ per container with the exception that plants at the Alabama site in 2011 was fertilized with Pro Fusion at $11 \mathrm{~g}$ per container $(5,8)$. Plants at all locations were maintained on outdoor irrigation pads and received overhead irrigation as needed. Typically irrigation was initiated daily between 7 a.m. and 8:30 a.m. for a 45- to 60-min duration.

Weather parameters. Air temperature, leaf wetness, and rainfall were recorded 25 to $50 \mathrm{~cm}$ above the ground and between plants at each location as described previously $(5,8)$. Spectrum leaf wetness sensors (Spectrum Technologies, Plainfield, IL) were used from 2006 to 2008 and recorded the instantaneous value of resistance over a grid on a scale from 0 (dry) to 15 (wet) every 15 min. Decagon leaf wetness sensors (Decagon Devices, Inc., Pullman, WA) were used from 2007 to 2011 and recorded the number of minutes within 30-min intervals when the dielectric constant exceeded 460 raw counts. In 2008, the two brands of leaf wetness sensors were used at opposite ends of a plot. In a preliminary comparison involving 1,008 30-min measurement periods at the TCSHL site in July 2008, both sensors simultaneously indicated dry conditions during 725 periods and wet conditions during 261 periods, giving an overall between-sensor concurrence of $97.8 \%$. From all sites, temperature, leaf wetness, and rainfall readings were summarized from June 16 to September 4. Daily maxima, averages, and totals were calculated as appropriate for each weather variable $(5,8)$.

Disease progress. Rhizoctonia leaf blight intensity (LBI), defined as the mean number of symptomatic leaves per plant, was assessed weekly in the temporal disease development trials and biweekly in the fungicide timing trials. In the temporal disease development trials, LBI was a mean from 15 randomly selected plants from a single block of 180 to 506 plants (8). In the fungicide timing trials, LBI was a mean of 36 plants (four replications of nine plants) from the untreated control treatment; data from the fungicide timing treatments were not used (5). For the current analysis, the initial LBI rating used was on or just after June 16 and the last LBI rating used was just before or on September 4. The data represents a natural disease progression uninterrupted by intervention with fungicide treatment; thus, an actual response from fungicide applications is not evaluated in this study. From this point, LBI will be used in a broader manner in conjunction with any reference to LBI values, including the original weekly or biweekly LBI values, and LBI values used to calculate risk and prediction values as explained in the following sections.

Statistical analyses of developmental data. Six site-year datasets (ALn-2007, TCSHL-2007, MSn-2008, TCSHL-2008, OHRC-2009, and TCSHL-2010) were randomly selected as developmental data for model selection, thus assigning the remaining five site-year datasets (MSn-2006, TCSHL-2006, MSn2007, TCSHL-2009, and TCSHL-2011) to validation data. Because of differences in the initial LBI values and the weekly or biweekly LBI patterns over time between the six developmental data-sets, a trial and error process was used to evaluate and select definitions for an "initial significant LBI value" and a "significant LBI increase." Both these terms are important for implementing the ROC procedure explained below. An initial significant LBI value of 16 or greater blighted leaves was selected to be the minimum value from which a subsequent significant LBI increase would be assessed. Selection of a significant LBI increase required it to be minimally responsive to the prominent up and down fluctuations in the LBIs that occurred in wetter seasons, as seen in Figure 1 of Copes and Scherm (8), without being insensitive to shallow increases in the LBIs that occurred in drier seasons, as seen in Figures 1 to 4 of Copes et al. (5). The irregular oscillating LBI pattern, particularly prominent in wetter years, resulted from episodic disease and plant growth cycles dominated either by leaf infection, leaf blight development and disease-induced leaf dehiscence, or new leaf growth. A LBI increase was selected to be significant when the current LBI value was an $18 \%$ or greater increase above the previous significant LBI or the initial significant LBI value, and a minimum of a 13-day interval had transpired since the last significant increase.

Significant increases in LBI were used to define case periods. For each site-year dataset, the web blight season was classified into periods called cases (a period in advance of a significant LBI increase when a preventive control action potentially could have been applied) and periods called controls (a period when preventive control potentially would have minor control impact). A case consisted of 14 contiguous days that started and ended, respectively, 16 and 3 days prior to a significant LBI increase. Any day not classified as a case by default was part of a control period. Controls were contiguous days that preceded or followed cases and varied in duration dependent on the frequency and placement of cases. At this step, cases and controls became fixed time periods individually patterned in each dataset according to the LBI progression.

Multiple models were arbitrarily explored where temperature, leaf wetness, and rainfall variables individually and in combination were assigned daily risk values that influenced the progressive development of web blight; some of the models tested are shown in Table 1. Each weather variable singularly and in combination took the assigned value defined by the model, if specific definitions were met. The value of the daily risk depended on whether 0 to 3 variables meet the criteria. The temperature variable, labeled TMP, took the assigned value when temperatures were between $20^{\circ} \mathrm{C}$ and $30^{\circ} \mathrm{C}$ for more than $18 \mathrm{~h}$ and the daily maximum was less than $35^{\circ} \mathrm{C}$; otherwise, TMP was ' 0 ' $(7,8)$. The leaf wetness variable, labeled LW, took the assigned value when leaf wetness $(\geq 4$ for Spectrum sensors and $\geq 10$ for Decagon sensors) was recorded daily for $16 \mathrm{~h}$ or more; otherwise, $\mathrm{LW}$ was ' 0 ' (4). The rainfall variable, labeled $\mathrm{Rf}$, took the assigned value when daily rainfall was $6.7 \mathrm{~mm}$ above the highest irrigation amount (specific to siteyear data); otherwise, $\mathrm{Rf}$ was ' 0 ' (5). When multiple weather variables were met, the appropriate assigned value was recorded as the daily risk value. The daily risk values were accumulated over time and referred to as an accumulated risk value (ARV). A critical risk value, termed a cutpoint, was selected to hypothetically predict 
need for a preventive control action. A cutpoint should be reached within each case and not within a control. Multiple cutpoints were evaluated to select the more accurate cutpoint value applied to a model. For each dataset, the ARV was started at zero on June 15, and accumulated across a control(s) and case(s) until equaling or exceeding the cutpoint value. The accumulation process was started over after each cutpoint was obtained. With some models, the ARV was set to zero and the accumulation process started the next day. In the final selection, the ARV was reset to zero for 7 days following the cutpoint value, and then the process of accumulating the ARV continued to a another cutpoint value. The ARV process was repeatedly performed until September 4 . The zeros following a cutpoint value created a 7-day delay before ARVs were accumulated to foster a minimum of a 14-day interval before a subsequent potential infection event could be indicated. At this step, the ARV and cutpoints became fixed values aligned with cases and controls.

Models and cutpoints were evaluated based on frequencies tabulated for true positives (TP), false negatives (FN), true negatives (TN), and false positives (FP). TP occurred when a cutpoint was reached within a case period, and FN occurred when the cutpoint was not reached within a case period. TN occurred when a cutpoint was not reached during the days of a control period, and FP occurred when a cutpoint was reached within a control period. TP, FN, TN, and FP were used to calculate true positive proportions (TPP $=$ number of TP / number of cases), false negative proportions $(\mathrm{FNP}=$ number of $\mathrm{FN} /$ number of cases, or $1-\mathrm{TPP})$, true negative proportions (TNP $=$ number of $\mathrm{TN} /$ number of controls), false positive proportions (FPP $=$ number of FP / number of controls, or $1-\mathrm{TNP})$, overall model accuracy $(=(\mathrm{TP}+\mathrm{TN}) /$ (number of cases + controls $)$ ), Youden's index $(=\mathrm{TPP}+\mathrm{TNP}-1)$, positive likelihood ratio $[\mathrm{LR}(+)=\mathrm{TPP} /(1-\mathrm{TNP})]$, and negative likelihood ratio $[\mathrm{LR}(-)=(1-\mathrm{TPP}) / \mathrm{TNP})]$ for each model $(10,16,18,19,21)$. Equivalent terminology used in some manuscripts, but not this one, are TPP = sensitivity, FNP $=1-$ sensitivity, TNP $=$ specificity, and $\mathrm{FPP}=1-$ specificity. Youden's Index is a measure of the overall non-error rate that weighs TPP and TNP equally; higher decimal values to a maximum of one indicate closer proximity of the cutpoint to the upper left graph point $(0,1)$ of the ROC curve $(16,21,25)$. The likelihood ratios are predictors of the binary test's capability to discriminate between cases and controls. The higher the $\mathrm{LR}(+)$ value is above 1 (indefinitely large is ideal), the more likely positive predictions are to come from cases than from controls. The closer the LR(-) value is to 0 (zero is ideal), the less likely negative predictions are to come from cases than from controls. Models with the combination of a higher Youden's Index, higher LR(+), and lower LR(-) were selected for ROC analysis.

Statistical analyses of ROC curves. Each control and case was classified as "negative" and "positive," respectively, for all six datasets. The ARV at the cutpoint or at the last day of a control or case was paired with the respective negative and positive classification, then sorted by ascending ARV order within each classification. The ARV was indexed against the control and case classification to determine the ability of a logistic regression to discriminate negative from positive test results. The logistic regression also generates an area under the ROC (AUROC) curve and associated statistics were produced using the ROC macro under the tools selection of SigmaPlot 12 (24). The ROC macro uses the trapezoidal rule to integrate area below curves, The $P$-value determines if the area value is significantly greater than 0.5 . Pairwise comparisons of ROC areas were made using the method of DeLong et al. (9).

Suitability of model cutpoints was further verified based on inspection of four plots: 1) dot histograms where high dot density should occur above and below the cutpoint value for cases and controls, respectively; 2) a major peak on the positive likelihood ratio line and low on the negative likelihood ratio line should align at or near the cutpoint; 3 ) the cutpoint value should align with inflection points in proximity to the crossover intersection of TPP and TNP lines; and 4) cutpoint positions on the ROC curve should occur in close proximity to either the upper left graph point $(0,1)$ or to the highest TPP value with a low $1-$ TNP value (19). The model with the most significant ROC area was subsequently used to analyze the five validation datasets.

Statistical analyses of validation data. The five remaining datasets (MSn-2006, TCSHL-2006, MSn-2007, TCSHL-2009, and TCSHL-2011) were used as validation data. The five datasets contained the days of the year (DOY) with control and case classifications and ARVs. The ARV was repeatedly accumulated to or above the cutpoint from June 16 to September 4, as previously described for development datasets. Frequencies of TP, TN, FP, and TP were tabulated and used to calculate TPP, TNP, overall accuracy,

Table 1. Daily risk values were assigned to temperature (TMP), leaf wetness (LW), rainfall (Rf), and all combinations of the three variables for each model to represent possible conditions that might promote Rhizoctonia web blight development on azalea

\begin{tabular}{|c|c|c|c|c|c|c|c|}
\hline \multirow[b]{2}{*}{ Model $^{w}$} & \multicolumn{7}{|c|}{ Model's daily risk value when weather criteria were met } \\
\hline & TMPx & $\mathbf{L W}^{\mathbf{y}}$ & TMP+LW & $\mathbf{R f}^{\mathbf{z}}$ & TMP+Rf & $\mathbf{L W}+\mathbf{R f}$ & TMP+LW+Rf \\
\hline S-1.1 & 2 & 1 & 3 & 1 & 3 & 1 & 3 \\
\hline S- 1.2 & 1.5 & 1 & 2.5 & 1 & 2.5 & 1 & 2.5 \\
\hline S-1.3 & 1 & 1 & 2 & 1 & 2 & 1 & 2 \\
\hline S-2.1 & 2 & 0.5 & 2.5 & 0.5 & 2.5 & 2.5 & 3 \\
\hline S-2.2 & 1.5 & 0.5 & 2 & 0.5 & 2 & 2 & 2.5 \\
\hline S-2.3 & 1 & 0.5 & 1.5 & 0.5 & 1.5 & 1.5 & 2 \\
\hline S-3.1 & 2 & 0.75 & 2.75 & 0.25 & 2.25 & 1 & 3 \\
\hline S-3.2 & 1.5 & 0.75 & 2.25 & 0.25 & 1.75 & 1 & 2.5 \\
\hline S-3.3 & 1 & 0.75 & 1.75 & 0.25 & 1.25 & 1 & 2 \\
\hline S-4.1 & 2 & 0 & 2 & 0 & 2 & 2 & 2 \\
\hline S- 4.2 & 1.5 & 0 & 1.5 & 0 & 1.5 & 1.5 & 1.5 \\
\hline S-4.3 & 1 & 0 & 1 & 0 & 1 & 1 & 1 \\
\hline N-A & 1 & 1 & 2 & 0 & 1 & 1 & 2 \\
\hline N-J & 1.2 & 1 & 1.7 & 0 & 1.2 & 1 & 1.7 \\
\hline $\mathrm{N}-\mathrm{K}$ & 1 & 1 & 1.5 & 0 & 1 & 1 & 1.5 \\
\hline $\mathrm{N}-\mathrm{H}$ & 0.7 & 1 & 1.7 & 0.5 & 1.2 & 1.5 & 2.2 \\
\hline N-M & 1.3 & 0.8 & 1.8 & 0.4 & 1.4 & 0.9 & 2 \\
\hline N-S & 0.6 & 0.7 & 1 & 0.2 & 1 & 0.7 & 1.2 \\
\hline $\mathrm{N}-\mathrm{W}$ & 0.4 & 0.8 & 0.9 & 0.2 & 0.9 & 0.8 & 1.1 \\
\hline
\end{tabular}

${ }^{\text {w}}$ Models were labeled as nonsystematic $(\mathrm{N})$ or systematic $(\mathrm{S})$ if changes between models were arbitrarily selected or followed a mathematical relationship, respectively, and by a numerical or alphabetical identification.

${ }^{x}$ The daily risk value arbitrarily assigned when daily temperature (TMP) was $>20^{\circ} \mathrm{C}$ and $<30^{\circ} \mathrm{C}$ for $>18 \mathrm{~h}$ and maximum $\mathrm{TMP}<35^{\circ} \mathrm{C}$; ' 0 ' otherwise.

y The daily risk value arbitrarily assigned when leaf wetness (LW) was $\geq 4$ for Spectrum conductance sensors and $\geq 10$ for Decagon dielectric sensors for $\geq 16$ $\mathrm{h}$; '0' otherwise.

${ }^{\mathrm{z}}$ The daily risk value arbitrarily assigned when daily rainfall (Rf) total was $>6.7 \mathrm{~mm}$ above the highest irrigation amount (specific to site-year data); ' 0 ' otherwise. 
Youden's index, LR(+), and LR(-). AUROC curves were produced, as previously described.

\section{Results}

Preliminary data analysis was required to define the initial significant LBI value, significant LBI increase, and case and cutpoint terms. The selection process showed a heterogeneity across datasets, assumed in part because of diverse weather conditions over 6 years. One dataset was particularly problematic. The ALn-2006 dataset had the highest initial LBI on June 16 and the lowest final LBI on September 15 , respectively, of three datasets collected during the wettest year of these studies (8). In combination with an atypical disease development pattern for ALn-2006, none of the cutpoints aligned with cases, while cutpoints aligned with each case in the MSn-2006 and SHL-2006 datasets. Because of the overall dissimilarity to other datasets, the ALn-2006 developmental dataset was dropped from the analysis. Further explanation is presented in the discussion.

Model N-W with a cutpoint of 4 had the highest overall accuracy of all other models, based on the criteria of having the highest Youden's index and LR(+), and the lowest LR(-), indicating it provided the highest predictive capability to achieve cutpoint values during case periods and seldom during control periods (Table 2). Most models had low accuracy measurements (data not shown). The other models in Table 2 had moderate levels of accuracy, but did not produce a significant AUROC curve (data not shown). Model N-W produced a significant AUROC curve $(0.772, P=$ $0.0120)$, with lower and upper confidence intervals $(0.597,0.963)$ above the discriminatory line (Fig. 1). The discriminatory line is the diagonal line that represents an equal frequency distribution of cutpoints for cases and controls.

The accuracy of model N-W was further evaluated in a dot histogram of the ARV values at the end day of every case and control (Fig. 2), and in line graphs of the TPP and TNP responses and of the $\operatorname{LR}(+)$ and $\operatorname{LR}(-)$ responses with cutpoints (Fig. 3). The dot histogram showed that most of the case and control ARVs were greater than and lesser than 4, respectively. Model N-W had 10 of the 13 cases with ARV values equal to or greater than 4.0 and 13 of the 17 controls with ARVs lower than 4.0 for the six developmental datasets (Table 2, Fig. 2). Cutpoint accuracy was further supported by the close proximity of 4.0 to the intersection of where the TPP and TNP lines crossed (Fig. 3A). The crossover point of the TPP and TNP lines aligned with cutpoint 3.95, which also aligned with the bend point closest to the upper left graph point $(1,0)$ on the ROC curve (Fig. 1). Cutpoint 3.95 was also associated with a high peak on the $\mathrm{LR}(+)$ line and a low value on the $\mathrm{LR}(-)$ line (Fig. 3B).
Only whole integer cutpoints were selected, but the ROC analysis showed 3.95 was optimal.

Model N-W produced higher measures of accuracy with the five validation datasets than with the developmental datasets (Table 2). The validation datasets produced a significant AUROC $(0.839, P=$ $0.0034)$ with lower and upper confidence intervals $(0.676,1.00)$ that were above the discriminatory line (Fig. 1). The histogram showed minor overlap of the ARV distributions between cases and controls. Model $\mathrm{N}-\mathrm{W}$ had 10 of the 12 cases with ARV values equal to or greater than 4.0 and 12 of the 14 controls with ARVs lower than 4.0 from the validation datasets (Fig. 2).

\section{Discussion}

Temperature, leaf wetness, and rainfall were shown to provide a measurable daily risk that accumulated over time to hypothetically predict need of a fungicide application to prevent significant LBI development under diverse weather conditions. The superior model $(\mathrm{N}-\mathrm{W})$ assigned the highest risk to leaf wetness, being twice that of temperature and four times that of rain, and nearly equal risk to all

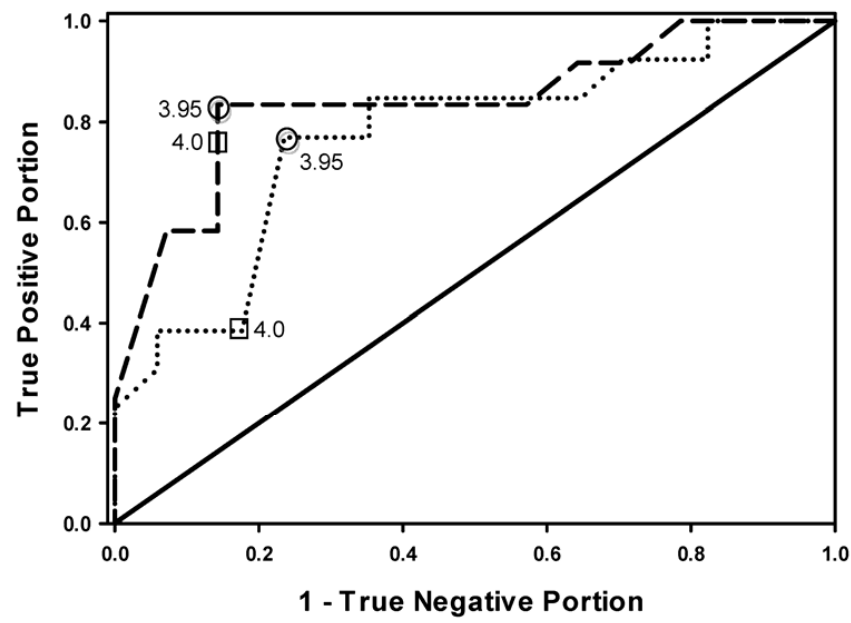

Fig. 1. Receiver operating characteristic (ROC) curves for model N-W generated from an analysis of six developmental (dotted line) and five validation (dashed line) site-year datasets that predict Rhizoctonia web blight based on temperature, leaf wetness, and rainfall patterns. Two cutpoints highlighted are the 4.0 value (open squares) used with model $\mathrm{N}-\mathrm{W}$ and the 3.95 value (open circles) indicated as an optimal value by the relationship of true positive and true negative proportions in Fig. 3. The solid diagonal line represents a 50:50 probability of predicting cases and controls correctly.

Table 2. Performance measurements based on receiver operating characteristics (ROC) curve analysis of predictive models that assign risk values to two (temperature and leaf wetness) or three (temperature, leaf wetness, and rainfall) weather variables used to accumulate to cutpoints that predict need of a potential control action within a 14-day window that precedes significant Rhizoctonia leaf blight increases on container-grown azalea; ROC analysis was performed with six developmental datasets and five validation datasets

\begin{tabular}{|c|c|c|c|c|c|c|c|c|c|c|c|}
\hline \multirow[b]{2}{*}{ Model $^{y}$} & \multirow[b]{2}{*}{ Cutpoint } & \multirow[b]{2}{*}{ Cases } & \multirow[b]{2}{*}{ Controls } & \multirow[b]{2}{*}{ True $\mathbf{P}^{\mathbf{z}}$} & \multirow[b]{2}{*}{ True N } & \multirow[b]{2}{*}{ TPP } & \multirow[b]{2}{*}{ TNP } & \multirow{2}{*}{$\begin{array}{c}\text { Overall } \\
\text { accuracy }\end{array}$} & \multirow{2}{*}{$\begin{array}{c}\text { Youden's } \\
\text { index }\end{array}$} & \multicolumn{2}{|c|}{ Likelihood ratio } \\
\hline & & & & & & & & & & $(+)$ & $(-)$ \\
\hline \multicolumn{12}{|c|}{ Development data, non-significant ROC area } \\
\hline $\mathrm{S}-2.1$ & 10 & 13 & 17 & 9 & 10 & 0.692 & 0.588 & 0.633 & 0.281 & 1.681 & 0.523 \\
\hline S-2.2 & 8 & 13 & 17 & 9 & 10 & 0.692 & 0.588 & 0.633 & 0.281 & 1.681 & 0.523 \\
\hline S-4.2 & 8 & 13 & 17 & 9 & 11 & 0.692 & 0.647 & 0.667 & 0.339 & 1.962 & 0.476 \\
\hline S-4.3 & 6 & 13 & 17 & 9 & 11 & 0.692 & 0.647 & 0.667 & 0.339 & 1.962 & 0.476 \\
\hline $\mathrm{N}-\mathrm{H}$ & 9 & 13 & 17 & 9 & 12 & 0.692 & 0.706 & 0.700 & 0.398 & 2.354 & 0.436 \\
\hline N-J & 7 & 13 & 17 & 8 & 11 & 0.615 & 0.647 & 0.633 & 0.262 & 1.744 & 0.594 \\
\hline \multicolumn{12}{|c|}{ Developmental data, significant ROC area } \\
\hline $\mathrm{N}-\mathrm{W}$ & 4 & 13 & 17 & 10 & 13 & 0.769 & 0.765 & 0.769 & 0.534 & 3.269 & 0.302 \\
\hline \multicolumn{12}{|c|}{ Validation data, significant ROC area } \\
\hline $\mathrm{N}-\mathrm{W}$ & 4 & 12 & 14 & 10 & 12 & 0.833 & 0.857 & 0.846 & 0.690 & 5.833 & 0.194 \\
\hline
\end{tabular}

${ }^{y}$ Models were labeled as nonsystematic $(\mathrm{N})$ or systematic $(\mathrm{S})$ if differences between models were arbitrarily selected or followed a mathematical relationship, respectively, and by a numerical or alphabetical identification.

${ }^{\mathrm{z}}$ True positive (True $\mathrm{P},=$ number of cases where a cutpoint occurred), true negative (True N, = number of controls where a cutpoint did not occur). True positive proportions (TPP = number of true positives / number of cases), true negative proportions (TNP = number of true negatives / number of controls), overall model accuracy (= (Number of true positives + number of true negatives) / (number of cases + number of controls)), Youden's index $(=$ TPP + TNP -1), Likelihood ratio (+) (= TPP / (1 - TNP)), Likelihood ratio (-) (= (1 - TPP) / TNP). 
multiple combinations of weather variables (Table 1). Model N-W was the only model that weighted leaf wetness risk higher than the temperature risk. The risk classifications of 16 or more hours of leaf wetness and/or 18 or more hours of temperature between 20 and $30^{\circ} \mathrm{C}$ when daily maximum temperature was less than $35^{\circ} \mathrm{C}$ are indicative of conditions that are not regularly met yet are considered favorable for binucleate Rhizoctonia infection and mycelium growth, respectively $(4,8)$. The rain risk of greater than $6.7 \mathrm{~mm}$ rain above the maximum daily irrigation is representative of common rainfall amounts that are not uniquely explanatory of pathological functions. The influence on web blight from rain is not clearly understood from this analysis.

ROC curve analysis provides a practical approach for selecting models and identifying cutpoints as a predictor of potential infection events. ROC curve procedures use the number of correctly and incorrectly predicted cases and controls to evaluate accuracy. In many plant pathology studies, case and controls were defined based on a binary classification of disease severity significance for a complete site-year $(10,21,25-27)$. This approach would not provide temporal fungicide timing options for web blight. Typically, two to three fungicide applications are required to control web blight on azalea most years, yet only one application may be needed during a drier summer. By defining cases as 14-day windows to apply a fungicide prior to significant LBI increases, 2 to 3 cases were created per site-year in normal to wetter years and 1 to 2 case(s) per site-year in dry years. Model N-W accurately predicted significant LBI changes despite up and down fluctuating LBIs over time, and differing weather conditions and maximum LBI values between site-years. Yet the model still had limitations. The need to drop the ALn-2006 dataset was an obvious discrepancy in model accuracy. ALn-2006 was atypical in that web blight symptoms were expressed earlier than normal, in early June, and those plants had one of the lower web blight development rates during a wet summer that should have been more favorable for blight development (8). The cause for the atypical pattern is unknown, but it may be associated with an unintended fungicide application at the nursery. A fungicide application would limit blight development and violate the assumption of developing the model based on a natural disease progression, as previously stated in the "Disease progress" section. Another possible issue is the selection of June 16 to start accumulating risk values. The date is appropriate for a typical year, but may institute an error in the risk accumulation if disease symptoms build earlier than the models starting date. The author has not seen such an early buildup in 7 years of field trials, and the limited disease development in the ALn-06 dataset did not occur at the other two sites in 2006.

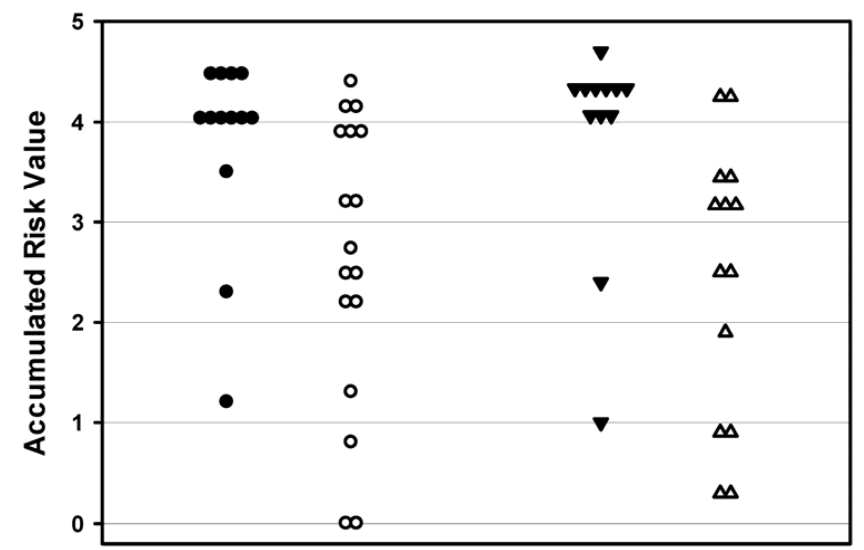

Fig. 2. Dot histogram of daily weather-based risk values that were accumulated to the end of cases (solid symbols, a positive period when fungicide intervention should prevent a significant web blight increase) that are expected to be $\geq 4$, and controls (open symbols, a negative period when a significant increase in web blight is not expected) that are expected to be $<4$, for the developmental model N-W (circles) and validation model N-W (triangles) datasets. Model N-W risk values for weather variables are summarized in Table 1.
The model needs field testing to critically evaluate fungicide timing efficacy. In the OHRC-2009 fungicide trial, one treatment received a fungicide application during two of three case periods, which resulted in the highest control or lowest web blight level of treatments in that site-year (5). In the TCSHL-2009 trial, fungicide was applied during one of two cases and resulted in the highest control. In the TCSHL-2011 trial, fungicide was applied 5 days prior to the only case period and resulted in the highest control. A function of ROC curve analysis is the ability to select a cutpoint that preferentially favors TPP or TNP depending on whether control or cost is more important, respectively. The general consensus has been that one or two unnecessary fungicide applications generally would be less costly than the resulting crop or yield loss $(10,21,25-27)$. From site-years where cutpoints were predicted near actual dates of fungicide applications, model results generally agree with fungicide application results with the caveat that the forecast model was calling for one application more than was actually needed to control web blight. It isn't known if additional control would have resulted from an additional fungicide application. Hughes et al. (17) discusses the uncertainty associated with ROC curve analysis due to cases and controls being classified by a sampling protocol typical of agricultural research, versus by a definitive test result done with individual assessments in medical clinic research. The sensitivity of model accuracy to initial significant LBI values and significant LBI increases supports their concerns.

Predictive models increase our capability to improve and evaluate plant disease management techniques that target specific and multiple components of plant disease cycles (11). In the case of the Rhizoctonia web blight on azalea model, accuracy may have been

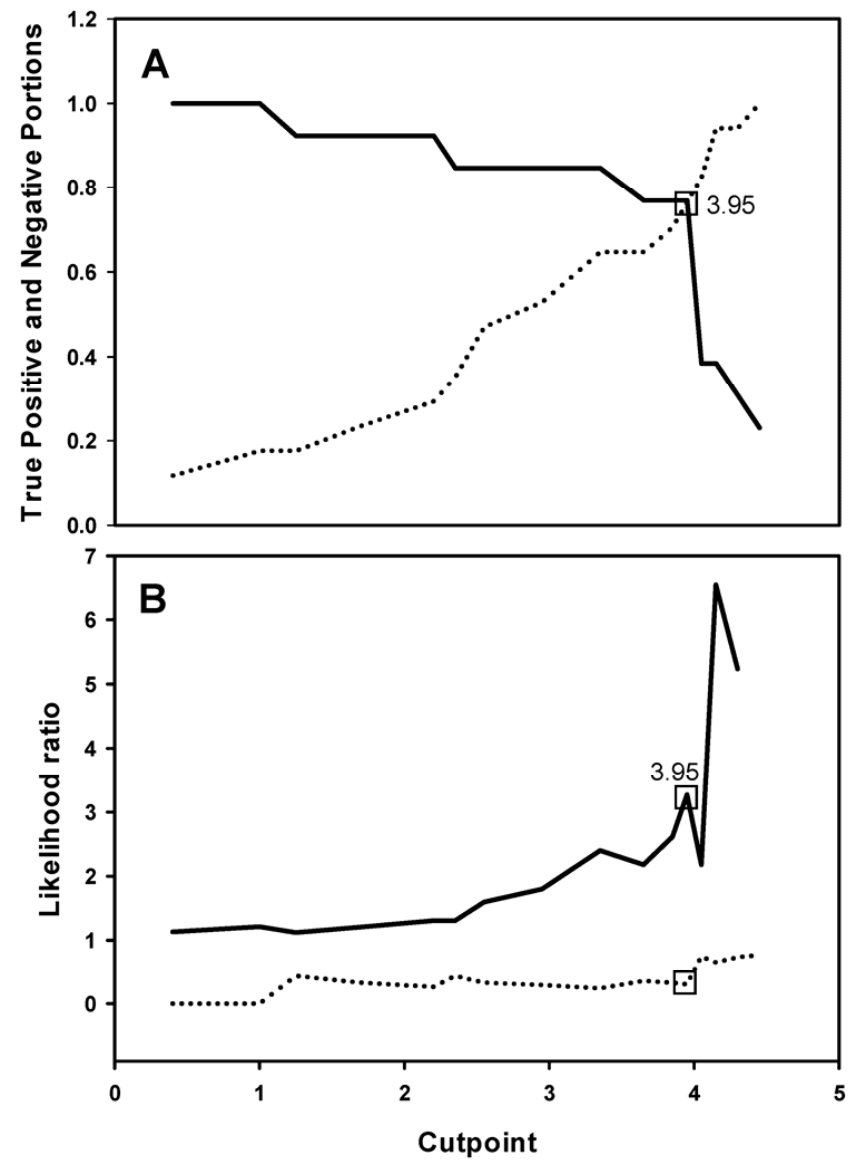

Fig. 3. Plots of the A, true positive proportion (TPP, solid line) and true negative proportion (TNP, dotted line) values, and B, the likelihood ratios (+) [solid line] and $(-)$ [dotted line] generated from receiver operating characteristic curves for developmental model $\mathrm{N}-\mathrm{W}$ as a function of a 4.0 cutpoint. The cutpoint (open square) at 3.95 highlights line traits that coincide with optimal balance between TPP and TNP and optimal positive and negative likelihood ratios for model N-W. 
improved by measuring additional components and conditions that influence web blight pathogenesis, such as: define weather conditions that promote infection, measure latent periods in response to weather, measure and combine the number of dehiscent leaves with LBI, and measure moisture and temperature patterns within the plant canopy. The author believes that measuring infection periods may be more important than latent periods. A rapid, synchronized leaf blight of hundreds of azaleas occurs over one to several days nearly annually. The infection and colonization process has not been histologically described and has not been correlated with specific weather conditions. Preliminary data by the author indicates that rapid azalea leaf blight may result predominately by infection of the leaf petiole versus leaf blades. Successive measurements of LBI would be more accurate and representative of disease development if it included the accumulative number of dehiscent leaves. This could minimize or eliminate the oscillating disease increase pattern. Moisture and temperature measurements were taken between plants. Many azalea cultivars have dense plant canopies; therefore, leaf wetness durations within the canopy may be longer and thus more favorable for disease development than conditions between plants. Miniature sensors and data loggers are being developed that would make these types of measurements feasible in the future.

The forecast model selected in this research establishes an accumulated weather-based risk prediction for Rhizoctonia web blight development on container-grown azalea produced under a daily irrigation regime. Currently, ornamental plant producers do not use any forecast models and likely would perceive a forecasting model as a prohibitive time demand, even when weather-based risk predictions require only simple calculations. A calendar-based schedule was developed for web blight (5). It is the simplest approach and has readily been adopted by many producers. A survey would be needed to see to what degree the industry will adopt scouting, which should be used in conjunction with a calendarbased schedule to adjust for year-to-year differences in timing. Undoubtedly, a weather-based forecast model would be more responsive to year-to-year differences. Additional field research would be required to maximize timing precision and efficacy of fungicide applications with a weather-based disease forecasting model.

\section{Acknowledgments}

I thank Harald Scherm, University of Georgia, for advisory support on statistical procedures and concepts and for reviewing the manuscript. The research was supported through the US Department of Agriculture, Agricultural Research Service, Thad Cochran Southern Horticultural Laboratory, Southern Horticultural Research Unit project number 6404-21430-001-00D.

\section{Literature Cited}

1. Ahuga, S. C., and Payak, M. M. 1981. Relationship of relative humidity and temperature levels with the development of leaf and sheath blight of maize. Z. Pflanzenkrankh. Pflanzenschutz 88:265-268.

2. Benson, D. M., and Jones, R. K. 2001. Rhizoctonia web blight. Pages 63-64 in: Diseases of Woody Ornamentals and Trees in Nurseries. R. K. Jones and D. M. Benson, eds. American Phytopathological Society, St. Paul, MN.

3. Bonde, M. R., Nester, S. E., and Berner, D. K. 2012. Effects of daily temperature highs on development of Phakopsora pachyrhizi on soybean. Phytopathology 102:761-768.

4. Copes, W. E. 2013. Rhizoctonia web blight development on azalea in relation to leaf wetness duration in the glasshouse. J. Phytopathol. 161:723-729.
5. Copes, W. E., Hagan, A., and Olive, J. 2012. Timing of fungicides in relation to calendar date, weather, and disease thresholds to control Rhizoctonia web blight on container-grown azalea. Crop Prot. 42:273-280.

6. Copes, W. E., Rodriguez-Carres, M., Toda, T., Rinehart, T. A., and Cubeta, M. A. 2011. Seasonal prevalence of species of binucleate Rhizoctonia fungi in growing medium, leaf litter and stems of container-grown azalea. Plant Dis. 95:705-711.

7. Copes, W. E., and Scherm, H. 2005. Plant spacing effect on microclimate and Rhizoctonia web blight development in container-grown azalea. HortScience 40:1408-1412.

8. Copes, W. E., and Scherm, H. 2010. Rhizoctonia web blight development on container-grown azalea in relation to time and environmental factors. Plant Dis. 94:891-897.

9. DeLong, E. R., DeLong, D. M., and Clarke-Pearson, D. L. 1988. Comparing the areas under two or more correlated receiver operating characteristic curves: a nonparametric approach. Biometrics 44:837-845.

10. Dewdney, M. M., Biggs, A. R., and Turechek, W. W. 2007. A statistical comparison of the blossom blight forecasts of MARYBLYT and Cougarblight with receiver operating characteristic curve analysis. Phytopathology 97:1164-1176.

11. De Wolf, E. D., and Isard, S. A. 2007. Disease cycle approach to plant disease prediction. Annu. Rev. Phytopathol. 45:203-220.

12. Fidanza, M. A., Dernoeden, P. H., and Grybauskas, A. P. 1996. Development and field validation of a brown patch warning model for perennial ryegrass turf. Phytopathology 86:385-390.

13. Frisina, T. A., and Benson, D. M. 1987. Characterization and pathogenicity of binucleate Rhizoctonia spp. from azalea and other woody ornamental plants with web blight. Plant Dis. 71:977-981.

14. Frisina, T. A., and Benson, D. M. 1989. Occurrence of binucleate Rhizoctonia spp. on azalea and spatial analysis of web blight in containergrown nursery stock. Plant Dis. 73:249-254.

15. Gross, M. K., Santini, J. B., Tikhonova, I., and Latin, R. 1998. The influence of temperature and leaf wetness duration on infection of perennial ryegrass by Rhizoctonia solani. Plant Dis. 82:1012-1016.

16. Hughes, G. 2012. Applications of Information Theory to Epidemiology. APS Press, St. Paul, MN.

17. Hughes, G., McRoberts, N., and Burnett, F. J. 1999. Decision-making and diagnosis in disease management. Plant Pathol. 48:147-153.

18. Linnet, K. 1988. A review on the methodology for assessing diagnostic tests. Clin. Chem. 34:1379-1386.

19. Madden, L. V. 2006. Botanical epidemiology: some key advances and its continuing role in disease management. Eur. J. Plant Pathol. 115:3-23.

20. Metz, C. E. 1978. Basic principles of ROC analysis. Nucl. Med. 4:283-298.

21. Pethybridge, S. J., Gent, D. H., Esker, P. D., Turechek, W. W., Hay, F. S., and Nutter, F. W., Jr. 2009. Site-specific risk factors for ray blight in Tasmanian pyrethrum fields. Plant Dis. 93:229-237.

22. Rinehart, T. A., Copes, W. E., Toda, T., and Cubeta, M. A. 2007. Genetic characterization of binucleate Rhizoctonia species causing web blight on azalea in Mississippi and Alabama. Plant Dis. 91:616-623.

23. Scherm, H., Ngugi, H. K., and Ojiambo, P. S. 2006. Trends in theoretical plant epidemiology. Eur. J. Plant Pathol. 115:61-73.

24. SigmaPlot 12. SigmaPlot Contents and Index. ROC curve analysis. Systat Software, San Jose, CA.

25. Turechek, W. W., Hartung, J. S., and McCallister, J. 2008. Development and optimization of a real-time detection assay for Xanthomonas fragariae in strawberry crown tissue with receiver operating characteristic curve analysis. Phytopathology 98:359-368.

26. Turechek, W. W., and Wilcox, W. F. 2005. Evaluating predictors of apple scab with receiver operating characteristic curve analysis. Phytopathology 95:679-691

27. Twengström, E., Sigvald, R., Svensson, C., and Yuen, J. 1998. Forecasting Sclerotinia stem rot in spring sown oilseed rape. Crop Prot. 17:405-411.

28. Yang, X. B., Snow, J. P., and Berggren, G. T. 1990a. Analysis of epidemics of Rhizoctonia aerial blight of soybean in Louisiana. Phytopathology 80:386-392.

29. Yang, X. B., Berggren, G. T., and Snow, J. P. 1990b. Effects of free moisture and soybean growth stage on focus expansion of Rhizoctonia aerial blight Phytopathology 80:497-503. 